\title{
Capturing Complete Spatial Context in Satellite Observations of Greenhouse Gases
}

\author{
Charles E. Miller*a , Christian Frankenberg ${ }^{\mathrm{a}, \mathrm{b}}$, Andreas C. Kuhnert ${ }^{\mathrm{a}}$, Gary D. Spiers ${ }^{\mathrm{a}}$, Annmarie \\ Eldering $^{\mathrm{a}}$, Mayer Rud ${ }^{\mathrm{a}}$, Thomas S. Pagano ${ }^{\mathrm{a}}$, Daniel W. Wilson ${ }^{\mathrm{a}}$, Cynthia Brooks ${ }^{\mathrm{c}}$, Daniel T. Jaffe ${ }^{\mathrm{c}}$ \\ ${ }^{a}$ Jet Propulsion Laboratory, California Institute of Technology, 4800 Oak Grove Drive, Pasadena, \\ CA, USA 91109-8099 \\ ${ }^{b}$ Division of Geology and Planetary Sciences, California Institute of Technology, 1200 E. California \\ Blvd., Pasadena, CA USA 91125 \\ ${ }^{\mathrm{c}}$ Department of Astronomy, University of Texas at Austin, Austin, TX 78712
}

\begin{abstract}
Scientific consensus from a 2015 pre-Decadal Survey workshop highlighted the essential need for a wide-swath (mapping) low earth orbit (LEO) instrument delivering carbon dioxide $\left(\mathrm{CO}_{2}\right)$, methane $\left(\mathrm{CH}_{4}\right)$, and carbon monoxide (CO) measurements with global coverage. OCO-2 pioneered space-based $\mathrm{CO}_{2}$ remote sensing, but lacks the $\mathrm{CH}_{4}, \mathrm{CO}$ and mapping capabilities required for an improved understanding of the global carbon cycle. The Carbon Balance Observatory (CARBO) advances key technologies to enable high-performance, cost-effective solutions for a space-based carbon-climate observing system. CARBO is a compact, modular, $15-30^{\circ}$ field of view spectrometer that delivers highprecision $\mathrm{CO}_{2}, \mathrm{CH}_{4}, \mathrm{CO}$ and solar induced chlorophyll fluorescence (SIF) data with weekly global coverage from LEO. CARBO employs innovative immersion grating technologies to achieve diffraction-limited performance with OCO-like spatial $\left(2 \times 2 \mathrm{~km}^{2}\right)$ and spectral $(\lambda / \Delta \lambda \approx 20,000)$ resolution in a package that is $>50 \%$ smaller, lighter and more costeffective. CARBO delivers a 25 - to 50 -fold increase in spatial coverage compared to OCO-2 with no loss of detection sensitivity. Individual CARBO modules weigh $<20 \mathrm{~kg}$, opening diverse new space-based platform opportunities.
\end{abstract}

Keywords: Carbon Dioxide $\left(\mathrm{CO}_{2}\right)$, Methane $\left(\mathrm{CH}_{4}\right)$, Carbon Monoxide (CO), satellite, remote sensing, wide-field, Low Earth Orbit (LEO), mapping

\section{INTRODUCTION}

There is an urgent need to better understand and predict the future role of the carbon cycle in the climate system [1]. Changes in atmospheric radiative forcing due to natural and anthropogenic emissions of the greenhouse gases carbon dioxide $\left(\mathrm{CO}_{2}\right)$ and methane $\left(\mathrm{CH}_{4}\right)$ will likely be the most important driver of climate change in the $21^{\text {st }}$ century. Human activities have caused unprecedented, rapid increases in atmospheric $\mathrm{CO}_{2}$ and $\mathrm{CH}_{4}$ concentrations since the beginning of the industrial era [2], with anthropogenic emissions forecasted to increase exponentially through 2050 [3]. Earth System feedbacks reduce or amplify the effects of those emissions on atmospheric concentrations, yet despite decades of research, carbon-climate feedbacks remain poorly quantified. It is critical to understand the relationship between climate forcing from anthropogenic emissions, climate-carbon cycle feedbacks, and the resulting atmospheric $\mathrm{CO}_{2}$ and $\mathrm{CH}_{4}$ concentrations in a changing climate [2]. This requires a mechanistic understanding of the global carbon cycle, including quantified space- and time-resolved patterns of anthropogenic emissions, natural sources and sinks, and the key processes controlling them [1]. "What processes control the rate of increase in atmospheric $\mathrm{CO}_{2}$ and $\mathrm{CH}_{4}$ and will these change in the future?" is the fundamental question of carbon-climate system science.

To address this question, we are developing the Carbon Balance Observatory (CARBO), a new generation of spacebased carbon cycle remote sensing technology. CARBO is designed to measurement requirements that will enable us to significantly improve our understanding of and our ability to predict the likely future trajectory of atmospheric $\mathrm{CO}_{2}$ and

Imaging Spectrometry XXI, edited by John F. Silny, Emmett J. lentilucci, Proc. of SPIE Vol. 9976, $997609 \cdot$ ? 2016 SPIE · CCC code: 0277-786X/16/\$18 · doi: 10.1117/12.2238766 
$\mathrm{CH}_{4}$. CARBO is a modular wide-swath (15-30 field of view) polarization insensitive spectrometer that will deliver $\mathrm{CO}_{2}$, $\mathrm{CH}_{4}, \mathrm{CO}$ and solar-induced chlorophyll fluorescence (SIF, a proxy for gross photosynthetic carbon uptake and vegetation health [4]) measurements with high accuracy and weekly global coverage at $\sim 2 \mathrm{~km}$ spatial resolution from low Earth orbit (LEO, Fig. 1). We exploit advances in immersion grating and electron beam lithography technologies to deliver CARBO's increased capability in a package that is $>50 \%$ smaller and lighter than the Orbiting Carbon Observatory (OCO-2) instrument. CARBO thus benefits from significant cost savings and increased satellite accommodation opportunities. An instrument with CARBO measurement capabilities is not feasible at a reasonable size and cost using the OCO-2 design strategy.

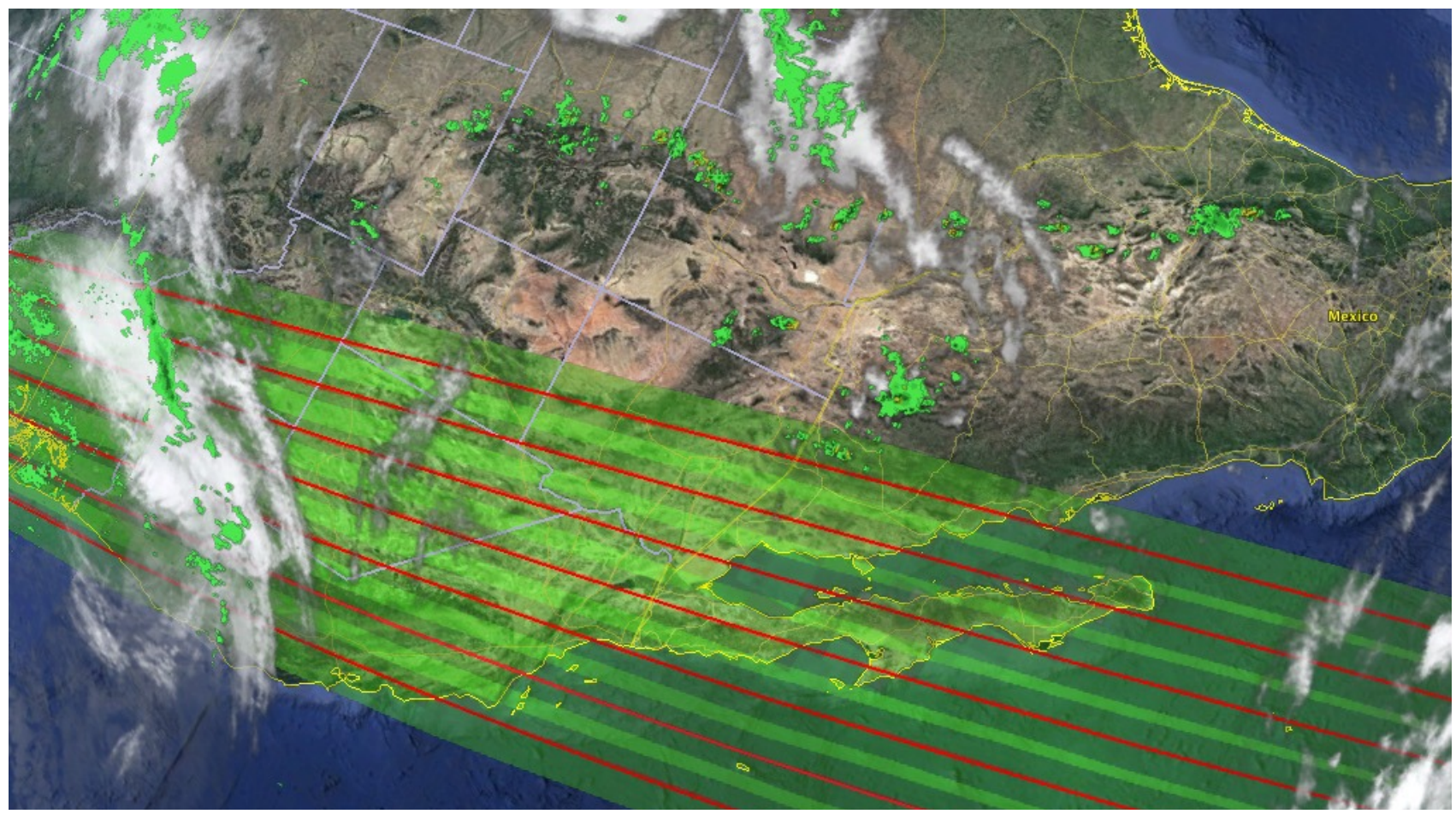

Figure 1. Comparison of OCO-2 (red lines, $\sim 10 \mathrm{~km}$ swath) and CARBO (green, $15^{\circ} \mathrm{FOV}$ ) spatial coverage over the western United States for 7 adjacent LEO orbit tracks ( $3 \%$ of one 16-day repeat cycle). One CARBO $15^{\circ}$ FOV module not only increases spatial coverage $\sim 25 \mathrm{x}$ vs OCO-2, but the brighter green areas show where adjacent CARBO swaths overlap for repeat sampling.

\section{CARBO OBJECTIVES \& SCIENCE REQUIREMENTS}

A complex interplay of natural and anthropogenic processes controls the atmospheric concentrations of $\mathrm{CO}_{2}$. Terrestrial ecosystems currently offset $\sim 25 \%$ of anthropogenic $\mathrm{CO}_{2}$ emissions due to a slight imbalance between global terrestrial photosynthesis (gross primary productivity, GPP) and respiration (ER). Understanding what controls GPP and ER is therefore crucial to predicting climate change [5]; however, there is no consensus on the global GPP, and large uncertainties exist in its benchmarking (Fig 2) [6]. GPP and ER fluxes are generally inferred from measurements of $\mathrm{CO}_{2}$ net ecosystem exchange (NEE = GPP - ER) since there is no way of directly measuring photosynthesis or respiration [5]. Similarly, there are important uncertainties in estimates of the magnitude and distribution of anthropogenic $\mathrm{CO}_{2}$ emissions [7], and these uncertainties will grow as the fraction of future anthropogenic emissions shifts to developing countries [8]. In fact, circa 2010 uncertainties in anthropogenic emissions dominate the global $\mathrm{CO}_{2}$ budget [9]. Concurrent measurements of $\mathrm{CO}_{2}$ and carbon monoxide $(\mathrm{CO})$ have proven a powerful approach for disentangling anthropogenic and combustion emissions from natural fluxes [10-12]. There is thus an urgent need to improve 
observation-based $\mathrm{CO}_{2}$, GPP and $\mathrm{CO}$ data sets as well as the representation of key natural and anthropogenic processes within carbon cycle models to accurately estimate the present $\mathrm{CO}_{2}$ budget and better quantify the future fraction of anthropogenic $\mathrm{CO}_{2}$ emissions that remain in the atmosphere [6].
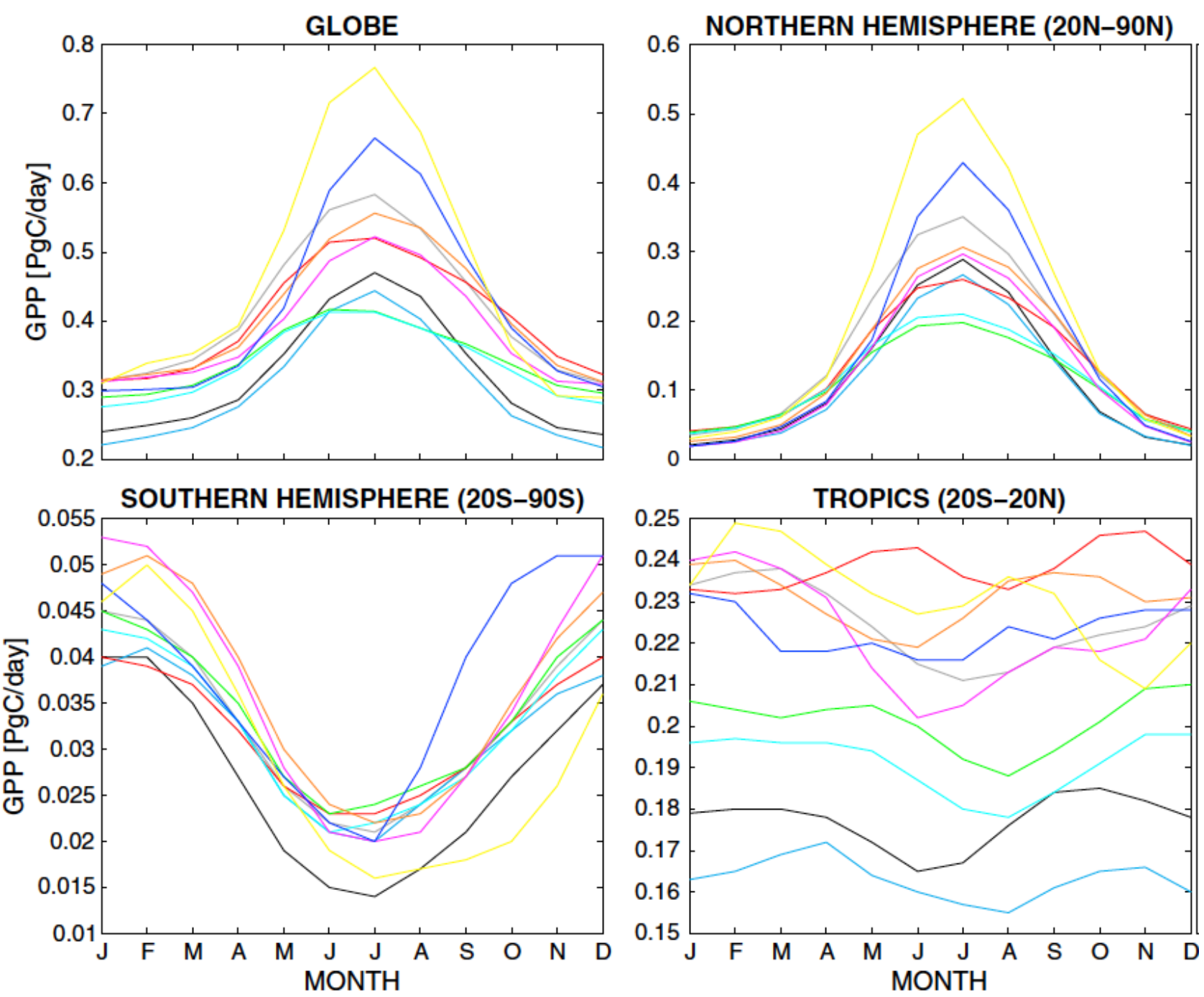

Figure 2. Different models show significant discrepancies in representations of the magnitude, shape and timing of the annual GPP (photosynthesis) cycle [6]. CARBO's enhanced SIF and high-sensitivity $\mathrm{CO}_{2}$ measurements combined with high spatial resolution and weekly global mapping will revolutionize our understanding of global GPP and photosynthesis.

The processes controlling the global budget of $\mathrm{CH}_{4}$ (Fig 3), the second most important anthropogenic greenhouse gas, are even more uncertain [13]. Numerous field studies have shown that inventories of anthropogenic $\mathrm{CH}_{4}$ emissions systematically underestimate observed emissions by $50-100 \%$ or more, particularly in major urban areas [14] or from natural gas systems [15]. Concentrations of atmospheric $\mathrm{CH}_{4}$ had stabilized in the early 2000s, but began abruptly increasing again in 2007 [16]. Changes in $\mathrm{CH}_{4}$ emissions from tropical wetlands [17], agriculture in Southern Asia [18], and increasing US fugitive emissions [19] have been proposed as the catalyst for this upturn, although the factors responsible for the observed stabilization and renewed rise remain unclear and can not be definitely resolved given uncertainties in the global $\mathrm{CH}_{4}$ budget [13]. The partitioning of $\mathrm{CH}_{4}$ emissions by region and process is poorly 
constrained by current atmospheric observations and would benefit from denser, more evenly distributed $\mathrm{CH}_{4}$ concentration data [13].

The current system of global atmospheric $\mathrm{CO}_{2}$ and $\mathrm{CH}_{4}$ measurements does not adequately constrain process-based carbon cycle models to allow diagnosis and/or attribution of carbon fluxes with confidence. Improving satellite observations of $\mathrm{CO}_{2}, \mathrm{CH}_{4}, \mathrm{CO}$ and SIF is necessary to advance our understanding of the carbon cycle, including necessary improvements in process-based models and their ability to predict future atmospheric $\mathrm{CO}_{2}$ and $\mathrm{CH}_{4}$ levels [20]. Expert consensus is that this could be achieved with "top-down" estimates of $\mathrm{CO}_{2}$ and $\mathrm{CH}_{4}$ surface fluxes monthly at $100 \mathrm{~km}$ spatial resolution $\left(\sim 1^{\circ} \mathrm{x} 1^{\circ}\right)$ by combining satellite data with atmospheric inversion models over several annual cycles [20]. $\mathrm{CO}$ and SIF measurements enhance $\mathrm{CO}_{2}$ and $\mathrm{CH}_{4}$ flux diagnosis and attribution.

Space-based measurements of the column averaged dry air mole fraction (denoted $\mathrm{X}_{\mathrm{GHG}}$ ) retrieved from high-resolution spectroscopic observations of reflected sunlight in near infrared $\mathrm{CO}_{2}$ and $\mathrm{CH}_{4}$ bands have the potential to significantly reduce carbon flux uncertainties [21]. OCO-2 $\left(\mathrm{X}_{\mathrm{CO} 2}\right)$ and GOSAT $\left(\mathrm{X}_{\mathrm{CO} 2}\right.$ and $\left.\mathrm{X}_{\mathrm{CH} 4}\right)$ pioneered this capability, but a much denser observational grid is needed to retrieve estimates of surface fluxes at the required spatial and temporal resolution $\left(\sim 1^{\circ} \times 1^{\circ}\right.$, monthly). Contiguous mapping at high spatial resolution provides the spatial context required to quantify and attribute natural and anthropogenic point sources.

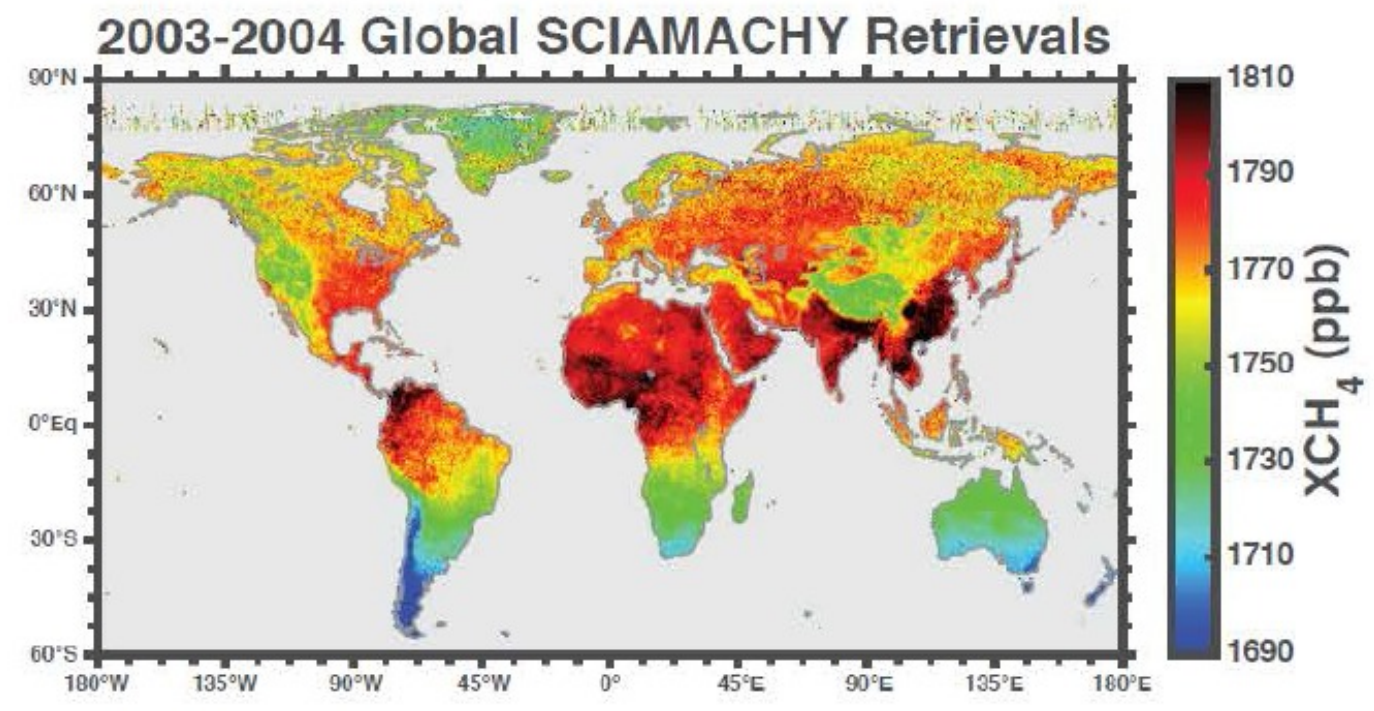

Figure 3. Global $\mathrm{X}_{\mathrm{CH} 4}$ retrievals from SCIAMACHY required 2 years of averaging to reveal key spatial patterns [23]. CARBO's weekly revisits, high sensitivity and high spatial resolution will yield critical insights on $\mathrm{CH}_{4}$ temporal dynamics for a mechanistic understanding of the underlying emissions processes.

OCO-2 is a grating spectrometer designed to retrieve $\mathrm{CO}_{2}$ using three near infrared spectral channels [22]. Its $\sim 3 \mathrm{~km}^{2}$ nadir spatial resolution maximizes cloud-free observations while its high spectral resolution and signal-to-noise ratio enable an unprecedented $1 \mathrm{ppm} \mathrm{X}_{\mathrm{CO} 2}$ retrieval precision [21]. OCO-2 is thus optimally suited to sample the global atmospheric $\mathrm{CO}_{2}$ distribution. However, the OCO-2 swath is only $10 \mathrm{~km}$ wide, meaning that it samples only $7 \%$ of the Earth's surface and does not provide the critical spatial context information that comes with complete mapping. Furthermore, OCO-2 is polarization sensitive and requires continuous satellite rotation to keep the instrument slit oriented perpendicular to the principal plane. This complicates operations and reduces the effective swath width from 10 $\mathrm{km}$ to as little as $1.3 \mathrm{~km}$. Finally, OCO-2 does not measure $\mathrm{CH}_{4}$ or $\mathrm{CO}$, limiting its effectiveness in carbon flux inversion studies, informed policy decisions, emissions monitoring, etc. 
CARBO's wide swath design enables full global mapping at high spatial resolution and weekly revisit times. CARBO's simultaneous $\mathrm{CO}_{2}, \mathrm{CH}_{4}, \mathrm{CO}$ and SIF measurements allow us to establish the functional relationships between $\mathrm{CO}_{2}, \mathrm{CH}_{4}$ and $\mathrm{CO}$ fluxes with environmental and biogeochemical controls such as soil moisture, vegetation type/structure, photosynthetic efficiency and vegetation stress [24-25]. These functional relationships enable the mechanistic understanding required to reliably project how major components of the climate-carbon cycle system such as tropical ecosystem exchange [26] or the permafrost carbon feedback [27] will respond to climate change. CARBO's weekly revisits better reveal $\mathrm{CO}_{2}, \mathrm{CH}_{4}$ and $\mathrm{CO}$ spatial gradients since these are more pronounced than monthly or seasonal averages. Complete mapping minimizes representativeness errors in inverse model flux estimates [28] and direct detection of point sources vs. local background, enabling simple emission estimates for sources like power plants, landfills, isolated wetlands, gas exploration, etc. [29]. Without mapping capabilities, detection and quantification of point sources would be fortuitous and defy robust attribution.

\subsection{CARBO Performance Requirements}

We quantified CARBO instrument performance requirements using our proposed wide-field immersion grating spectrometer design. Radiometric simulations indicate that the CARBO design achieves $>90 \%$ of the OCO-2 instrument SNR specifications by filling the FPA and enhancing throughput by a factor 1.3-1.5 as a result of immersion grating technology. CARBO's estimated $1.5 \mathrm{ppm}$ single measurement precision $\mathrm{X}_{\mathrm{CO} 2}$ sensitivity is thus similar to OCO-2. We also evaluated performance requirements for $\mathrm{X}_{\mathrm{CH} 4}, \mathrm{X}_{\mathrm{CO}}$ and SIF. We found that the detection of $\mathrm{CO}_{2}$ and $\mathrm{CH}_{4}$ can be combined within a single $1600 \mathrm{~nm}$ channel at somewhat lower spectral resolution without loss of accuracy [30]. This way, $\mathrm{CO}_{2}$ and $\mathrm{CH}_{4}$ can be measured in one band and the $\mathrm{CH}_{4}$ proxy retrieval method [10,31] employed. Sensitivity tests showed that the CARBO design (based on radiometric performance estimates of the proposed optical design and Hawaii-class focal plane array detectors like those flown on OCO-2) could achieve $7 \mathrm{ppb} \mathrm{X}_{\mathrm{CH} 4}$ single measurement precision for typical scenes. Sensitivity studies for the $2350 \mathrm{~nm}$ region (not shown here) indicate the CARBO design achieves a $5 \mathrm{ppb}$ single measurement precision in $\mathrm{X}_{\mathrm{CO}}$. CARBO $\mathrm{X}_{\mathrm{CO} 2}, \mathrm{X}_{\mathrm{CH} 4}$ and/or $\mathrm{X}_{\mathrm{CO}}$ detection sensitivities are consistent with pre-flight estimates from instruments with similar SNR and spectral resolution such as TropOMI [32] and CarbonSat [33].

CARBO introduces a major improvement in SIF detection sensitivity by extending the $\mathrm{O}_{2}$ A-band spectral range to 740 $\mathrm{nm}$. This improves the single measurement precision by $3 \mathrm{x}$ compared to sensors limited to the $758-772 \mathrm{~nm}$ window $(0.1$ $\mathrm{m}^{-2} \mu \mathrm{m}^{-1} \mathrm{sr}^{-1}$ vs. $0.3 \mathrm{~m}^{-2} \mu \mathrm{m}^{-1} \mathrm{sr}^{-1}$ for GOSAT, OCO-2, TropOMI, etc., Fig. 4). Typical SIF values range from $0.0-1.8$ $\mathrm{W} \mathrm{\textrm {m } ^ { - 2 }} \mathrm{m}^{-1} \mathrm{sr}^{-1}$ (equivalent to a $0-10 \mathrm{gC} / \mathrm{m} 2 /$ day gross $\mathrm{CO}_{2}$ flux), thus CARBO's enhanced SIF (SIF*) will track variations in SIF (hence GPP) with 5-10\% relative precision. This precision is required to investigate the diurnal cycle of fluorescence yield, which links direct to photosynthetic light use efficiency, a key uncertainty in carbon cycle models. 


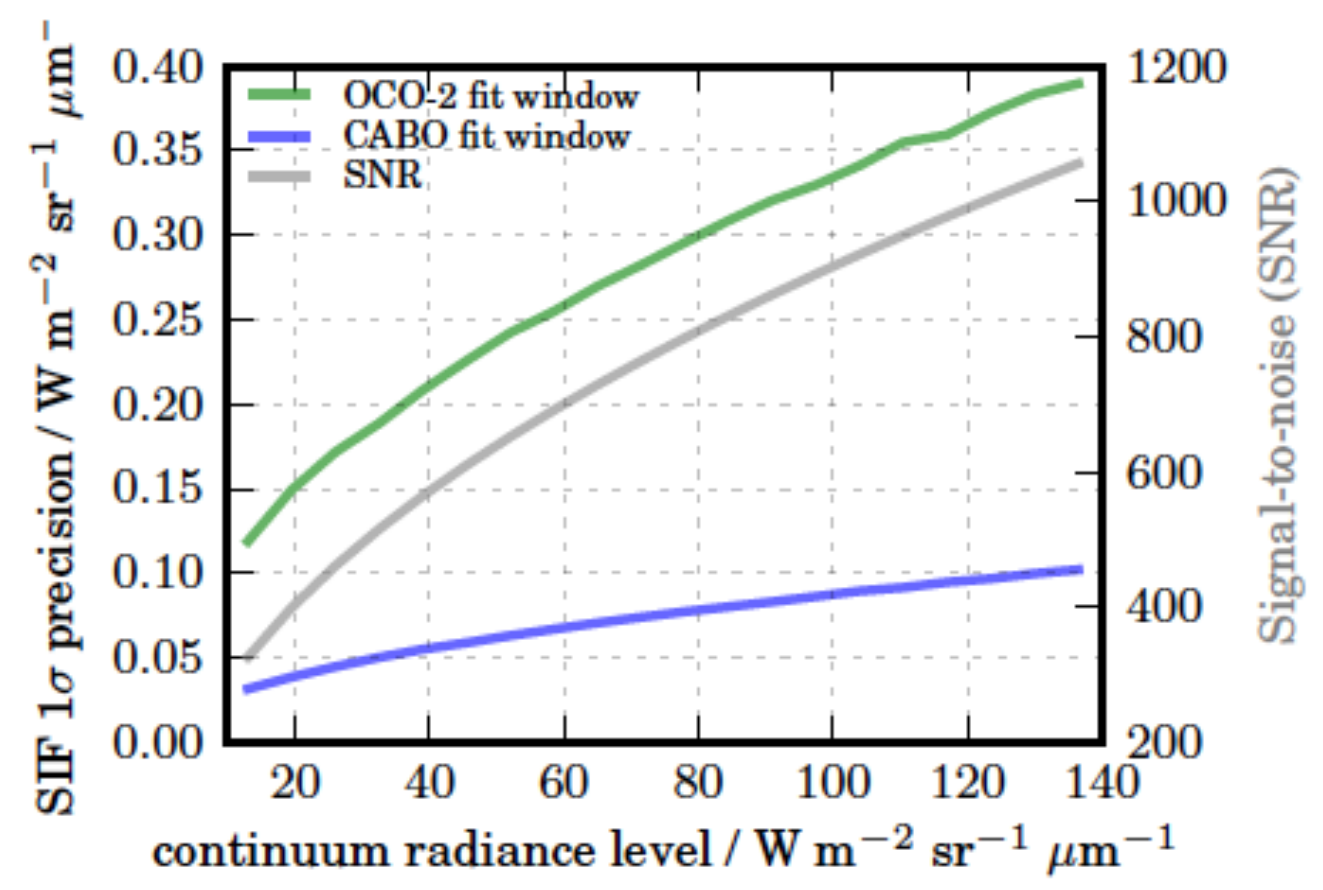

Figure 4. CARBO (blue line) improves SIF detection sensitivity 3-4x compared to OCO-2 (green line) by extending the SIF spectral range to $740 \mathrm{~nm}$. Radiometric simulations indicate that CARBO SIF will achieve better than $0.1 \mathrm{~W} \mathrm{~m}^{-2} \mu \mathrm{m}^{-1} \mathrm{sr}^{-1}$ precision across the expected range of continuum radiance levels.

\section{CARBO TECHNOLOGY INNOVATIONS}

CARBO advances and matures the key technologies required to create the next generation of space-based greenhouse gas remote sensing instruments. State of the art immersion grating technology lies at the heart of CARBO's innovative spectrometers. Immersion gratings reduce the anamorphic magnification, spherical aberration, and astigmatism that limited the OCO-2 spectrometers. CARBO's immersion grating design yields significantly improved imaging of the FOV on the FPA in both the spectral and spatial dimensions, which in turn enables the use of the entire FPA area even for megapixel $(1024 \times 1024$ or $1 \mathrm{Kx} 1 \mathrm{~K})$ and larger (e.g. $2 \mathrm{Kx} 2 \mathrm{~K}$, etc.) FPAs. This translates directly into increased spatial sampling and spectral range with the same spatial- and spectral-resolution as OCO-2 while reducing instrument size and mass. We combine these advantages with state of the art electron beam lithography for exquisite, atomic-level control of the grating groove structure (Fig 5) to reduce stray light below the $10^{-4}$ level and create polarization insensitive spectrometer response. 

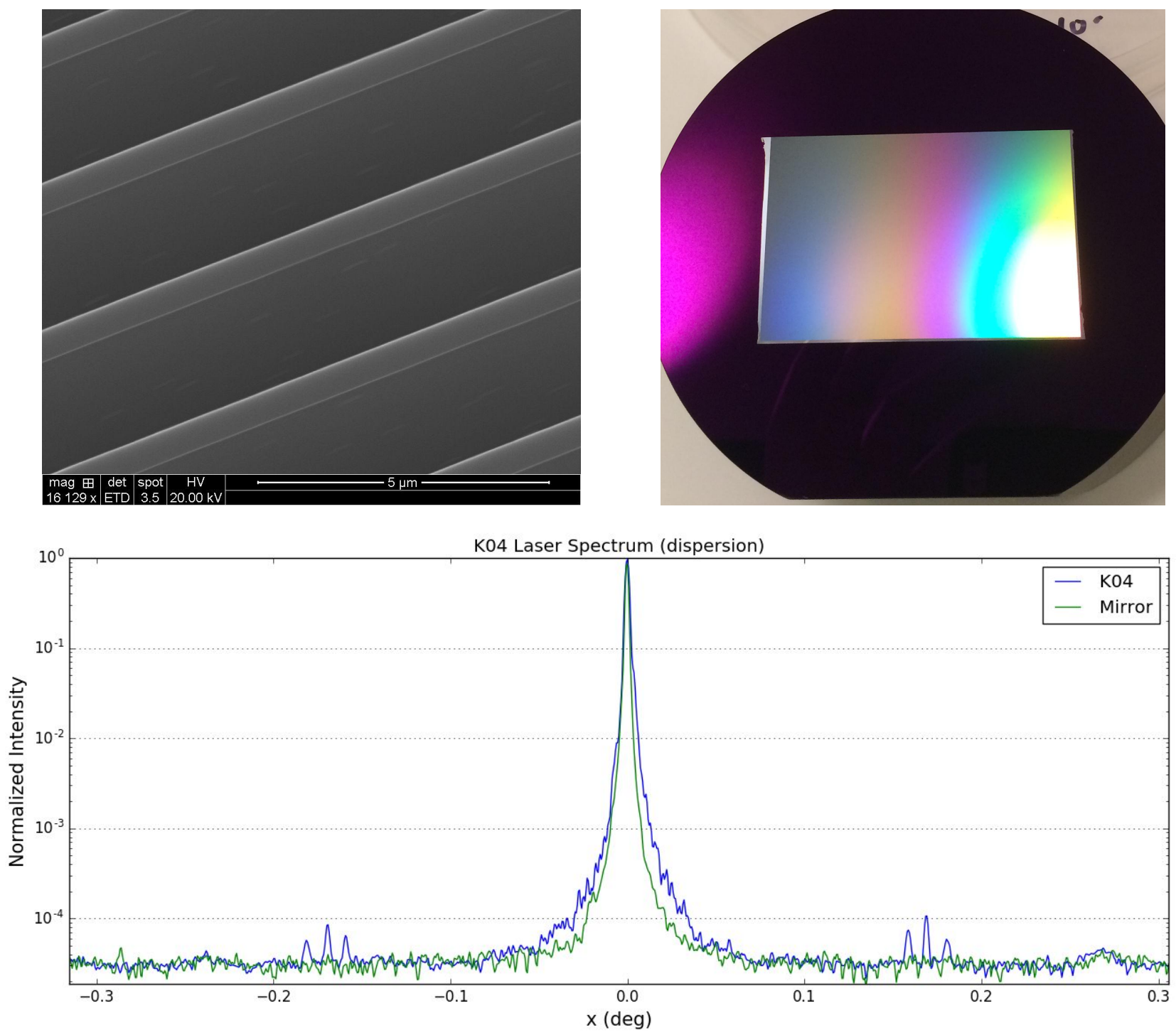

Figure 5. Images of the groove structure, completed prototype grating and stray light characteristics of a Si immersion grating fabricated to CARBO characteristics under the UT/JPL ACT project [34].

CARBO's other major technological innovation is its use of modular channels packaged in structural housings with identical form factors and dedicated telescopes. We required a compact, autonomous, modular architecture to facilitate adaptation to multi-mission needs. CARBO provides scalable system solutions for different measurement and platform requirements. The OCO instrument design - with its monolithic 3-channel housing, common telescope and dichroic beam splitters - made it impossible to increase the number of spectral channels and impractical to simultaneously measure neighboring spectral channels like the $1.65 \mu \mathrm{m} \mathrm{CH}_{4}$ and $1.61 \mu \mathrm{m} \mathrm{CO}$ bands. Our preliminary 4-channel design indicates that the CARBO approach cannot yield the full $30^{\circ} \mathrm{FOV}$ required for weekly global mapping in each spectral channel. Splitting the target $30^{\circ} \mathrm{FOV}$ into $15^{\circ} \mathrm{FOV}$ units for the 2-channel system simplifies the optical design, enables use of reasonably sized immersion gratings $(<30 \mathrm{~mm})$, improves instrument performance and greatly reduces overall instrument size, weight and cost. A fully functional 4-channel CARBO instrument would fit within the NASA Earth Ventures Instrument (EV-I) cost cap. Specifications of the channels and key requirements are given in Table 1. 
Table 1. Key CARBO Requirements

\begin{tabular}{|l|l|l|l|l|}
\hline CARBO Requirement & Channel 1 & Channel 2 & Channel 3 & Channel 4 \\
\hline Spectral Range (nm) & $740-772$ & $1598-1659$ & $2045-2080$ & $2305-2350$ \\
\hline Measurement Targets & $\mathrm{O}_{2}{ }^{\mathrm{a}}, \mathrm{SIF}^{*}$ & $\mathrm{CO}_{2}, \mathrm{CH}_{4}$ & $\mathrm{CO}_{2}$ & $\mathrm{CO}, \mathrm{CH}_{4}, \mathrm{H}_{2} \mathrm{O}^{\mathrm{b}}$ \\
\hline SNR @ 5\% albedo & $>300$ & $>350$ & $>150$ & $>100$ \\
\hline FWHM (nm) & 0.05 & 0.15 & 0.10 & 0.12 \\
\hline
\end{tabular}

${ }^{\text {a }}$ Target properties: The $\mathrm{O}_{2} \mathrm{~A}$-band is used for surface pressure, cloud \& aerosol properties

${ }^{\mathrm{b}}$ Also $\mathrm{HDO}, \mathrm{H}_{2}{ }^{17} \mathrm{O}$ and $\mathrm{H}_{2}{ }^{18} \mathrm{O}$ isotopologues as tracers of evapotranspiration and atmospheric mixing

${ }^{\mathrm{c}}$ Stated SNR values are the minimum required for $5 \%$ albedo, $60^{\circ}$ solar zenith angle observing conditions

Table 2. Key CARBO technology advances, comparison to OCO-2, and descriptions of CARBO scientific and mission benefits relative to current technologies

\begin{tabular}{|l|l|l|l|l|}
\hline Technology & \multicolumn{1}{|c|}{..affects... } & \multicolumn{1}{|c|}{ OCO-2 } & CARBO & Benefits of CARBO Technology Advances \\
\hline Wide FOV & $\begin{array}{l}\text { Global } \\
\text { Coverage }\end{array}$ & $0.15 \%$ /day & $15 \% /$ day & $\begin{array}{l}\text { Derivation of regional carbon fluxes on } \\
\text { weekly time scales; complete mapping }\end{array}$ \\
\hline $\begin{array}{l}\text { Immersion } \\
\text { Gratings }\end{array}$ & Grating angles & $\begin{array}{l}\alpha \sim 55^{\circ} \\
\beta \sim 73^{\circ} \\
100: 0\end{array}$ & $\begin{array}{l}\alpha \sim 33^{\circ} \\
\beta \sim 48^{\circ} \\
50: 50\end{array}$ & $\begin{array}{l}\text { Reduction in anamorphic magnification, } \\
\text { enhanced throughput } \\
\text { No need for active slit alignment, simplified } \\
\text { operations and retrieval algorithms } \\
\text { Size and cost reduction }\end{array}$ \\
\hline $\begin{array}{l}\text { 4 Spectral } \\
\text { Channels }\end{array}$ & $\begin{array}{l}\text { Geophysical } \\
\text { Variables }\end{array}$ & $\mathrm{CO}_{2}, \mathrm{SIF}$ & $\begin{array}{l}\mathrm{CO}_{2}, \mathrm{SIF}^{*}, \\
\mathrm{CH}_{4}, \mathrm{CO}\end{array}$ & $\begin{array}{l}\text { Quantifying the entire carbon budget, } \\
\text { disentangling natural and anthropogenic } \\
\text { fluxes, source attribution }\end{array}$ \\
\hline $\begin{array}{l}\text { Channel } \\
\text { Modularity }\end{array}$ & $\begin{array}{l}\text { No. Channels, } \\
\text { Design } \\
\text { flexibility } \\
\text { Redesign cost }\end{array}$ & $\begin{array}{l}\text { Partially } \\
\text { Modular }\end{array}$ & $\begin{array}{l}\text { Fully } \\
\text { Modular }\end{array}$ & $\begin{array}{l}\text { Adding/removing channels without redesign, } \\
\text { Redundancy } \rightarrow \text { Risk Reduction (no single } \\
\text { point failures) cost reduction on future } \\
\text { instrument development }\end{array}$ \\
\hline
\end{tabular}

Below we describe CARBO's Immersion Grating and Modular Spectrometer Design technology innovations. Key technological advances plus their scientific and mission-related benefits are listed in Table 2.

\subsection{CARBO Technology Innovation: Immersion Gratings}

CARBO exploits immersion gratings to break the size-resolving power constraints of traditional spectrometer designs [35]. An immersion grating is a diffractive device where the light is incident on the grating from inside a dielectric medium [36]. The reduced wavelength of light in this high-index medium improves performance by increasing the effective phase delay between adjacent grooves by a factor equal to the refractive index. This reduces the required grating size to achieve a desired spectral resolution, and in high index materials like silicon ( $\mathrm{Si}, n=3.4)$, this can result in significantly more compact devices or devices operating at much smaller incidence angles. The UT IGRINS astronomical spectrograph yields diffraction-limited spectra and no measured performance limitations attributable to its 
Si immersion grating [37]. CARBO optical designs leverage these properties to achieve $>50 \%$ reduction in mass and volume compared to OCO-2 while maintaining comparable SNR, spectral- and spatial-resolution and increasing spectral range.

The University of Texas (UT) silicon diffractive optics group produces silicon immersion gratings using microlithographic and chemical etching techniques. Under a recently completed ACT award, the UT/JPL team successfully fabricated prototype silicon immersion gratings with the characteristics appropriate for CARBO channels 2 - 4 (Fig 5), significantly reducing CARBO implementation risk [34]. The techniques developed during the ACT task will enable us to fabricate CARBO Si immersion gratings in $<24$ months.

Silicon is opaque in the 740-772 nm spectral range and cannot be used for CARBO's Ch. 1. Instead, we will use a glass prism coated with polymer e-beam resist, fabricating grating grooves by grayscale ebeam exposure followed by aqueous-based etching until the desired blaze angle is achieved. This is similar to the processes used by JPL to make the space-qualified gratings for Hyperion (EO-1), CRISM (Mars Reconnaissance Orbiter), ARTEMIS (TacSat-3), and Moon Mineralogy Mapper (Chandrayaan-1). A prototype for the CARBO glass immersion grating (groove period $1.28 \mu \mathrm{m}$, blaze angle $39^{\circ}$ ) was successfully fabricated under a JPL Research \& Technology Development task. We verified that it meets the small spectrometer size factor despite its lower index of refraction $(n \approx 1.5)$.

\subsection{CARBO Technology Innovation: Modular Instrument/Telescope Design}

In CARBO's modular architecture each spectral channel is an autonomous unit having its own telescope, optics and detector. The modular concept is achieved by designing all spectral channels to fit in identical housings, which are integrated into an overall instrument assembly. The inclusion of carefully placed fiducials on the individual units will allow mechanical tolerances to ensure the co-alignment requirements are met without the need for extensive and timeconsuming alignment procedures at the instrument level. Detailed performance testing can then be done on the individual spectrometers, allowing the use of smaller chambers and simpler optical ground support equipment. This approach maximizes the reuse of alignment fixtures and metrology equipment. A modular concept following this approach could be easily adjusted to varying scientific needs and/or resource constraints without the need to redesign the entire instrument (e.g. descoping FOV from $30^{\circ}$ to $15^{\circ}$ or decreasing the number of spectral channels).

A CARBO design with $15^{\circ}$ FOV (bi-weekly global coverage) would weigh $<65 \mathrm{~kg},<50 \%$ of OCO-2 despite a $25-50 \mathrm{x}$ swath increase. Conceptual similarities can be observed for instance in the camera design. Two major advantages of CARBO's immersion grating are apparent: 1) the overall spectrometer unit is far smaller despite the larger FOV and 2) the large grating angles in OCO-2 are relaxed in the CARBO design (see Table 2), ensuring a more homogeneous optical performance across the entire focal plane array and allowing a polarization insensitive design. These changes increase CARBO throughput, enabling OCO-2 like SNR and eliminate the need for rotating the instrument FOV to align with the principal plane. 


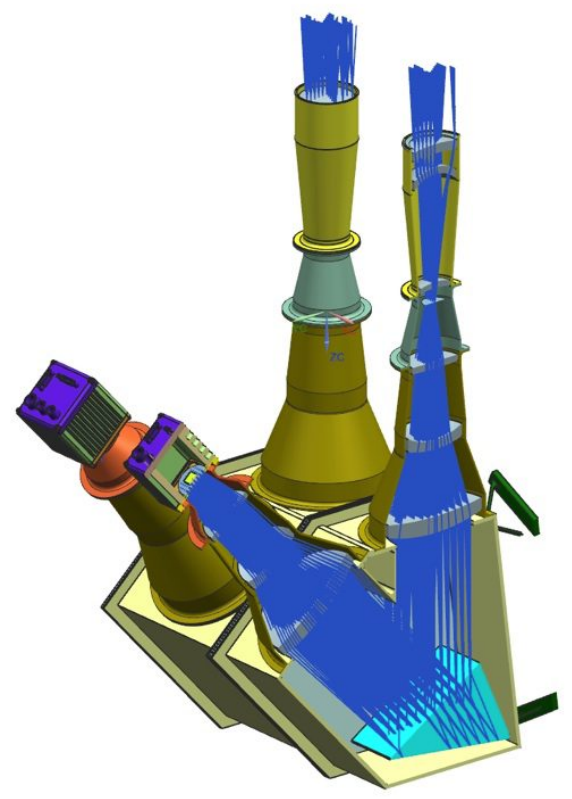

Figure 6. An optomechanical rendering of a 2-channel CARBO spectrometer with a cutaway of one channel to reveal its optical ray trace. Light enters the telescope from the top of the figure, travels through the immersion grating (light blue prism at the base of the spectrometer) and is the directed onto the detector (purple cube). All CARBO spectral channels fit within the same modular housing, greatly enhancing the ability to expand or redesign spectrometers for different uses or platforms.

\section{COMPARING CARBO TO EXISTING TECHNOLOGY}

There is no single current or planned satellite instrument that delivers CARBO's combination of accurate $\mathrm{CO}_{2}, \mathrm{CH}_{4}, \mathrm{CO}$ and SIF weekly global mapping at high spatial resolution. The strengths and weaknesses of various approaches are summarized in Table 3.

The closest comparison from a technological viewpoint is the TropOMI instrument (LRD late 2016), which will pioneer the immersion grating spectrometer for Earth observations from space [38]. However, TropOMI lacks the critical $\mathrm{CO}_{2}$ channel, and compared to CARBO its $\sim 7 \mathrm{~km} \times 7 \mathrm{~km}$ spatial resolution diminishes its sensitivity to point sources by $\sim 12 \mathrm{x}$ and decreases its estimated number of cloud free scenes by $\sim 2 \mathrm{x}$ [21]. ESA's CarbonSat candidate mission (a traditional grating design) had similar measurement requirements to CARBO, but lacked the CO channel critical for flux attribution, and was considered too much cost risk for EE8 selection. Parametric cost models project CARBO's compact, lightweight design to fall well within the EV-I cost cap, while CARBO's modular nature and use of proven technologies significantly reduces implementation risk. CARBO delivers the essential $\mathrm{CH}_{4}$ and $\mathrm{CO}$ measurements OCO-2 lacks while adding weekly mapping in a more compact, cost-effective package. CARBO nearly matches OCO-2 spectral resolution, spatial resolution, and SNR performance while delivering 3-4x improvement in SIF detection sensitivity. CARBO's polarization insensitive design simplifies operations and enables CARBO to fly on any platform with a dedicated nadir viewing deck. 
Table 3. Comparative Technology Assessment of GHG Remote Sensing Satellites

\begin{tabular}{|l|l|l|l|l|c|c|c|}
\hline \multicolumn{1}{|c|}{ Sensor } & $\mathbf{C O}_{\mathbf{2}}$ & $\mathbf{C H}_{\mathbf{4}}$ & $\mathbf{C O}$ & SIF & $\begin{array}{c}\text { Global } \\
\text { Coverage }\end{array}$ & $\begin{array}{c}\text { Fine Spatial } \\
\text { Resolution }\end{array}$ & Weekly Revisit \\
\hline CARBO & $1.5 \mathrm{ppm}$ & $7 \mathrm{ppb}$ & $5 \mathrm{ppb}$ & $<10 \%$ & Yes & $\sim 2 \mathrm{~km}$ & 7 days \\
\hline OCO-2 & $1.0 \mathrm{ppm}$ & N/A & N/A & $30 \%$ & $\sim 7 \%$ & $\sim 2 \mathrm{~km}$ & 16 days \\
\hline GOSAT & $1.5 \mathrm{ppm}$ & $30 \mathrm{ppb}$ & N/A & $30 \%$ & $\sim 2 \%$ & $\sim 10 \mathrm{~km}$ & 3 days \\
\hline GHGSat & TBD & TBD & N/A & N/A & TBD & $\sim 0.1 \mathrm{~km}$ & 14 days \\
\hline TropOMI & N/A & $<18 \mathrm{ppb}$ & $<10 \mathrm{ppb}$ & $30 \%$ & Yes & $\sim 7 \mathrm{~km}$ & 7 days \\
\hline TanSat & $1-4 \mathrm{ppm}$ & N/A & N/A & TBC & $7 \%$ TBC & $\sim 10 \mathrm{~km}$ & 16 days \\
\hline MERLIN & N/A & $10 \mathrm{ppb}$ & N/A & N/A & $\sim 1 \%$ & $50-100 \mathrm{~km}$ & 16 days \\
\hline MicroCarb & $1.0 \mathrm{ppm}$ & N/A & N/A & TBD & $3 \%$ & $\sim 6 \mathrm{~km}$ & 16 days \\
\hline ASCENDS & $2.0 \mathrm{ppm}$ & N/A & N/A & N/A & $\sim 1 \%$ & $50-100 \mathrm{~km}$ & 16 days \\
\hline CarbonSat & $1.2 \mathrm{ppm}$ & $7 \mathrm{ppb}$ & N/A & $30 \%$ & Yes & $\sim 2 \mathrm{~km}$ & 3 days \\
\hline
\end{tabular}

\section{CONCLUSIONS \& OUTLOOK}

We have presented a preliminary optomechanical design for CARBO, an innovative modular, high-sensitivity remote sensing instrument designed to deliver weekly global maps of $\mathrm{CO}_{2}, \mathrm{CH}_{4}, \mathrm{CO}$ and SIF from low Earth orbit. CARBO fills a critical gap in the Earth Science satellite program [39-43] and advances key technologies - immersion gratings and a modular design - to enable high-performance, cost-effective solutions for a carbon-climate observing system. Additionally, its compact, low-mass design opens up options for deployment on platforms ranging from smallsats to the International Space Station. Work continues to develop ground-based and airborne versions of CARBO to fully demonstrate these technologies and validate measurements from the current generation of greenhouse gas satellite sensors.

\section{ACKNOWLEDGMENTS}

Some of this work was supported by NASA ACT grant NNX12AC31G. A portion of this research was carried out at the Jet Propulsion Laboratory, California Institute of Technology, under contract with the National Aeronautics and Space Administration. (C) 2016. All rights reserved.

\section{REFERENCES}

[1] Schimel, D. et al. (2016), Observing the Carbon-Climate System, arXiv:1604:02106, https://arxiv.org/abs/1604.02106

[2] Stocker, T.F., D. Qin, G.-K. Plattner, M. Tignor, S.K. Allen, J. Boschung, A. Nauels, Y. Xia, V. Bex, and P.M. Midgley, eds., (2013), IPCC, 2013: Climate Change 2013: The Physical Science Basis. Contribution of Working Group I to the Fifth Assessment Report of the Intergovernmental Panel on Climate Change, 1535 pp, Cambridge Univ. Press, Cambridge, U. K. and New York. 
[3] Meinshausen, M., Smith, S.J., Calvin, K., Daniel, J.S., Kainuma, M.L.T., Lamarque, J.F., Matsumoto, K., Montzka, S.A., Raper, S.C.B., Riahi, K. and Thomson, A.G.J.M.V., (2011). The RCP greenhouse gas concentrations and their extensions from 1765 to 2300. Climatic Change, 109(1-2), pp.213-241.

[4] Frankenberg, C., et al. (2012b) Remote sensing of near-infrared chlorophyll fluorescence from space in scattering atmospheres: implications for its retrieval and interferences with atmospheric $\mathrm{CO}_{2}$ retrievals., Atmospheric Measurement Techniques 5.8: 2081-2094.

[5] Wehr, R., et al. (2016) Seasonality of temperate forest photosynthesis and daytime respiration., Nature 534.7609: 680-683.

[6] Anav, A., et al. (2015), Spatiotemporal patterns of terrestrial gross primary production: A review, Rev. Geophys., 53, 785-818, doi:10.1002/2015RG000483.

[7] Marland, Gregg, Khrystyna Hamal, and Matthias Jonas. (2009) How uncertain are estimates of CO2 emissions?, Journal of Industrial Ecology 13.1: 4-7.

[8] Guan, Dabo, et al. (2012) The gigatonne gap in China/'s carbon dioxide inventories., Nature Climate Change 2.9: 672-675.

[9] Le Quéré, C. Le, et al. (2015) Global carbon budget 2014., Earth System Science Data 7.1: 47-85.

[10] Frankenberg, C., U. Platt, and T. Wagner. (2005) Retrieval of CO from SCIAMACHY onboard ENVISAT: detection of strongly polluted areas and seasonal patterns in global CO abundances., Atmospheric Chemistry and Physics 5.6: 1639-1644.

[11] Palmer, Paul I., et al. (2006) Using CO2: CO correlations to improve inverse analyses of carbon fluxes., Journal of Geophysical Research: Atmospheres 111.D12.

[12] Wang, Huiming, et al. (2009) Error correlation between CO 2 and CO as constraint for CO 2 flux inversions using satellite data., Atmospheric Chemistry and Physics 9.19: 7313-7323.

[13] Kirschke, Stefanie, et al. (2013) Three decades of global methane sources and sinks., Nature Geoscience 6.10: 813823.

[14] Wennberg, P.O., Mui, W., Wunch, D., Kort, E.A., Blake, D.R., Atlas, E.L., Santoni, G.W., Wofsy, S.C., Diskin, G.S., Jeong, S. and Fischer, M.L., 2012. On the sources of methane to the Los Angeles atmosphere. Environmental science \& technology, 46(17), pp.9282-9289.

[15] Brandt, A.R., Heath, G.A., Kort, E.A., O'Sullivan, F., Pétron, G., Jordaan, S.M., Tans, P., Wilcox, J., Gopstein, A.M., Arent, D. and Wofsy, S., 2014. Methane leaks from North American natural gas systems. Science, 343(6172), pp.733-735.

[16]Dlugokencky, E. J., et al. (2009) Observational constraints on recent increases in the atmospheric CH4 burden., Geophysical Research Letters 36.18.

[17]Dlugokencky, E.J., Nisbet, E.G., Fisher, R. and Lowry, D., (2011) Global atmospheric methane: budget, changes and dangers. Philosophical Transactions of the Royal Society of London A: Mathematical, Physical and Engineering Sciences, 369(1943), pp.2058-2072.

[18] Schaefer, H., Fletcher, S.E.M., Veidt, C., Lassey, K.R., Brailsford, G.W., Bromley, T.M., Dlugokencky, E.J., Michel, S.E., Miller, J.B., Levin, I. and Lowe, D.C., (2016) A 21st-century shift from fossil-fuel to biogenic methane emissions indicated by 13CH4. Science, 352(6281), pp.80-84.

[19] Turner, A. J., et al. (2016) A large increase in US methane emissions over the past decade inferred from satellite data and surface observations., Geophysical Research Letters.

[20] Moore III, B., D. Schimel, P. Sellars, (2015) The Carbon-Climate System: An Advance Planning "Pre-Decadal Survey" Workshop. 15-18 March 2015. Final Report. http://cce.nasa.gov/cce/pdfs/final_carbon_climate.pdf

[21] Miller, C.E., et al. (2007). Precision requirements for space-based $X_{\mathrm{CO} 2}$ data. J. Geophys. Res.112, D10314. doi:10.1029/2006JD007659.

[22] Crisp, David, et al. (2004) The orbiting carbon observatory (OCO) mission., Advances in Space Research 34.4: 700709.

[23] Jacob, D. J., Turner, A. J., Maasakkers, J. D., Sheng, J., Sun, K., Liu, X., Chance, K., Aben, I., McKeever, J., and Frankenberg, C.: Satellite observations of atmospheric methane and their value for quantifying methane emissions, Atmos. Chem. Phys. Discuss., doi:10.5194/acp-2016-555, in review, 2016.

[24] Lichtenthaler, Hartmut K., and Joseph A. Miehé. (1997) Fluorescence imaging as a diagnostic tool for plant stress., Trends in plant science 2.8: 316-320.

[25]Zarco-Tejada, Pablo J., Victoria González-Dugo, and José AJ Berni. (2012) Fluorescence, temperature and narrowband indices acquired from a UAV platform for water stress detection using a micro-hyperspectral imager and a thermal camera." Remote Sensing of Environment 117: 322-337. 
[26] Schimel, D., Stephens, B.B. and Fisher, J.B., (2015) Effect of increasing $\mathrm{CO}_{2}$ on the terrestrial carbon cycle. Proceedings of the National Academy of Sciences, 112(2), pp.436-441.

[27] Schuur, E. A. G., et al. (2015) Climate change and the permafrost carbon feedback., Nature 520.7546: 171-179.

[28] Alkhaled, A. A., A. M. Michalak, and S. R. Kawa. (2008), Using CO2 spatial variability to quantify representation errors of satellite $\mathrm{CO} 2$ retrievals, Geophysical research letters 35.16 .

[29] Bovensmann, H., et al. (2010) A remote sensing technique for global monitoring of power plant CO 2 emissions from space and related applications., Atmospheric Measurement Techniques 3.4: 781-811.

[30] Frankenberg, C., et al. (2012a) Aerosol information content analysis of multi-angle high spectral resolution measurements and its benefit for high accuracy greenhouse gas retrievals., Atmospheric Measurement Techniques 5.7: 1809-1821.

[31] Frankenberg, C., U. Platt, and T. Wagner. (2005a) Iterative maximum a posteriori (IMAP)-DOAS for retrieval of strongly absorbing trace gases: Model studies for $\mathrm{CH}_{4}$ and $\mathrm{CO}_{2}$ retrieval from near infrared spectra of SCIAMACHY onboard ENVISAT., Atmospheric Chemistry and Physics 5.1: 9-22.

[32] Butz, A., et al. (2012) TROPOMI aboard Sentinel-5 Precursor: Prospective performance of CH 4 retrievals for aerosol and cirrus loaded atmospheres., Remote Sensing of Environment 120: 267-276.

[33] Buchwitz, M., Reuter, M., Bovensmann, H., Pillai, D., Heymann, J., Schneising, O., Rozanov, V., Krings, T., Burrows, J. P., Boesch, H., Gerbig, C., Meijer, Y., and Löscher, A. (2013) Carbon Monitoring Satellite (CarbonSat): assessment of atmospheric $\mathrm{CO}_{2}$ and $\mathrm{CH}_{4}$ retrieval errors by error parameterization, Atmos. Meas. Tech., 6, 3477-3500, doi:10.5194/amt-6-3477-2013.

[34] Jaffe, D. (2015). Development of Immersion Gratings to Enable a Compact Architecture for High Spectral and Spatial Resolution Imaging. NASA Grant NNX12AC31G. Final Report

[35] Park, Chan, et al. (2014) Design and early performance of IGRINS (immersion grating infrared spectrometer)., SPIE Astronomical Telescopes + Instrumentation. International Society for Optics and Photonics.

[36] Marsh, Jasmina P., Oleg A. Ershov, and Daniel T. Jaffe. (2003) Silicon grisms and immersion gratings produced by anisotropic etching: testing and analysis., Astronomical Telescopes and Instrumentation. International Society for Optics and Photonics.

[37] Gully-Santiago, Michael A., et al. (2014) High performance Si immersion gratings patterned with electron beam lithography., SPIE Astronomical Telescopes + Instrumentation. International Society for Optics and Photonics.

[38] Veefkind, J.P., Aben, I., McMullan, K., Förster, H., De Vries, J., Otter, G., Claas, J., Eskes, H.J., De Haan, J.F., Kleipool, Q. and Van Weele, M., 2012. TROPOMI on the ESA Sentinel-5 Precursor: A GMES mission for global observations of the atmospheric composition for climate, air quality and ozone layer applications. Remote Sensing of Environment, 120, pp.70-83.

[39] National Research Council. Earth Science and Applications from Space: National Imperatives for the Next Decade and Beyond. Washington, DC: The National Academies Press, 2007. doi:10.17226/11820.

[40] NASA (2010), Responding to the challenge of climate and environmental change: NASA's plan for a climate-centric architecture for Earth observations and applications from space, report, 48 pp., Washington, D. C.

[41] Pacala, Stephen W., et al. (2010) Verifying greenhouse gas emissions: methods to support international climate agreements., Committee on Methods for Estimating Greenhouse Gas Emissions.

[42] Michalak, Anna M., et al. (2009) A US Carbon Cycle Science Plan: First Meeting of the Carbon Cycle Science Working Group; Washington, DC, 17-18 November 2008., Eos, Transactions American Geophysical Union 90.12: 102103.

[43](2014) CEOS Strategy for Carbon Observations from Space. The Committee on Earth Observation Satellites (CEOS) Response to the Group on Earth Observations (GEO) Carbon Strategy. Issued date: September 302014 